\title{
Correction to: Bio-electrospraying is a safe technology for delivering human adipose-derived stem cells
}

\author{
Chuan Ye $\cdot$ Zhixu He $\cdot$ Yunfeng Lin $\cdot$ Yi Zhang $\cdot$ Jin Tang $\cdot$ Bo Sun • \\ Minxian Ma $\cdot$ Jielin Liu $\cdot$ Long Yang $\cdot$ Houxiang Ren $\cdot$ Baoping Zhao
}

Published online: 19 February 2021

(C) Springer Nature B.V. 2021

\section{Correction to:}

Biotechnology Letters (2015) 37:449-456

https://doi.org/10.1007/s10529-014-1693-0

In the published version of Fig. 2, images at $1 \mathrm{~h} 0 \mathrm{kV}$ and $10 \mathrm{kV}$ overlap with image $5 \mathrm{kV}$. The corrected version of Fig. 2 shows new images for $1 \mathrm{~h}-0 \mathrm{kV}$ and $10 \mathrm{kV}$. The authors regret their oversight during figure assembly and would like to sincerely apologize for this error. This unintentional error has no bearing on the article's scientific conclusion.

The original article can be found online at https:// doi.org/10.1007/s10529-014-1693-0.

C. Ye $(\bowtie) \cdot$ J. Tang $\cdot$ B. Sun $\cdot$ J. Liu ·

L. Yang $\cdot$ H. Ren $\cdot$ B. Zhao

Department of Orthopaedics, The Affiliated Hospital of Guiyang Medical College, Guiyang, China

e-mail: yechuanchina@hotmail.com

C. Ye $\cdot$ Z. He $(\varangle) \cdot$ M. Ma

Center for Tissue Engineering and Stem Cells, Guiyang Medical College, 9 Beijing Road, Guiyang 550004, China e-mail: hezixugy@sina.com

Y. Lin

Department of Oral and Maxillofacial Surgery, West China College of Stomatology, Sichuan University,

Chengdu, China

\section{Y. Zhang}

Department of Ultrasound, The Forty-Fourth Military

Hospital, Guiyang, China 


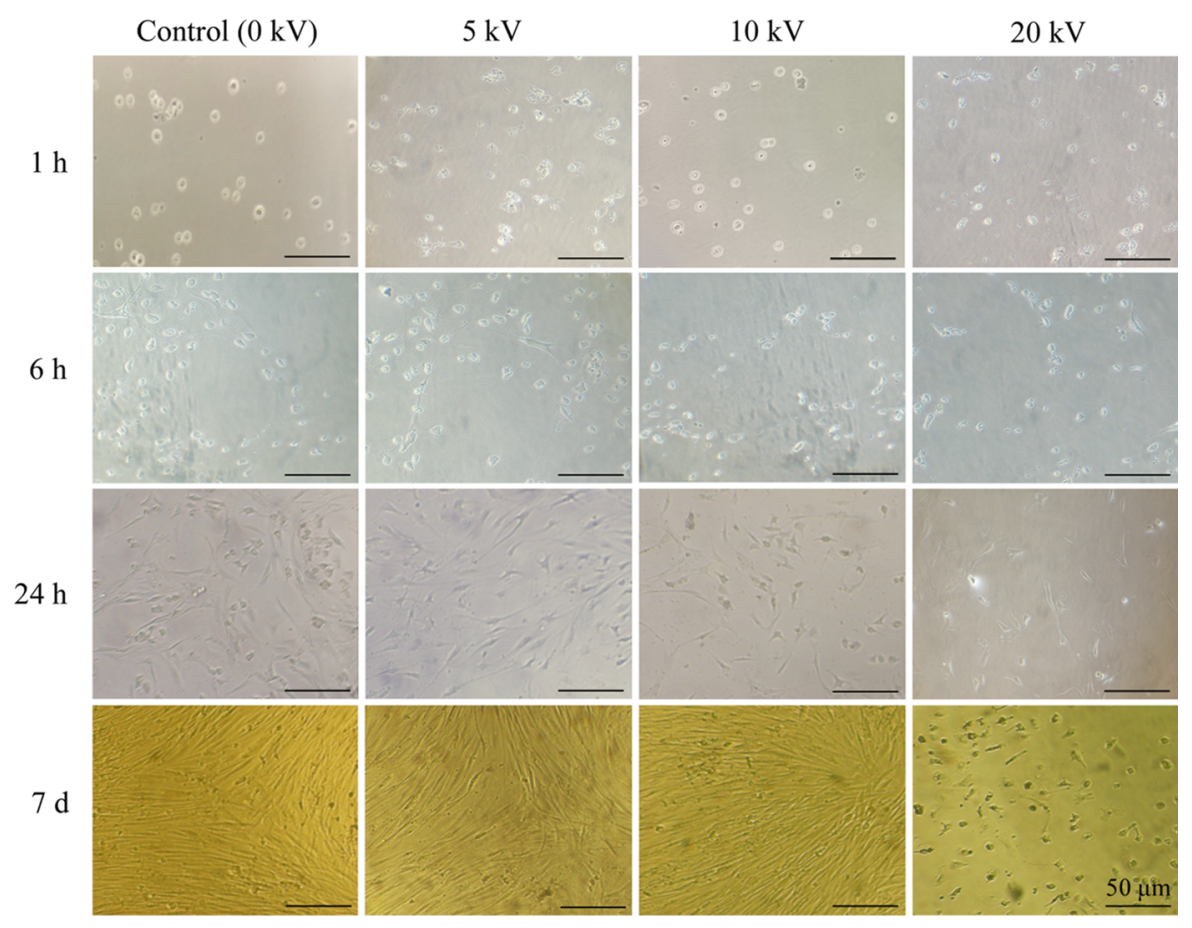

Fig. 2 These micrographs show the attachment and proliferation of the control and electrosprayed hASCs (the 5 and $10 \mathrm{kV}$ groups); BES did not alter cell viability. In contrast, hASCs electrosprayed at $20 \mathrm{kV}$ nearly always failed to attach and proliferate, confirming loss of viability. Scale bar $50 \mu \mathrm{m}$

Publisher's Note Springer Nature remains neutral with regard to jurisdictional claims in published maps and institutional affiliations. 